\title{
Spleen Tyrosine Kinase Inhibitor TAK-659
}

National Cancer Institute

\section{Source}

National Cancer Institute. Spleen Tyrosine Kinase Inhibitor TAK-659. NCI Thesaurus.

Code C113162.

An inhibitor of spleen tyrosine kinase (syk), with potential anti-inflammatory,

immunomodulating, and antineoplastic activities. Spleen tyrosine kinase inhibitor TAK-659

may inhibit the activity of syk, which abrogates downstream B-cell receptor (BCR)

signaling and leads to an inhibition of B-cell activation, chemotaxis, adhesion and

proliferation. Syk, a BCR-associated non-receptor tyrosine kinase that mediates diverse

cellular responses, including proliferation, differentiation, and phagocytosis, is expressed

in hematopoietic tissues and is often overexpressed in hematopoietic malignancies. 